\title{
Eficiência Nutricional de Cultivares de FeiJão em Competição com Plantas Daninhas ${ }^{1}$
}

\author{
Nutritional Efficiency of Bean Cultivars under Competition with Weeds \\ CURY, J.P. ${ }^{2}$, SANTOS, J.B. ${ }^{3}$, SILVA, E.B. ${ }^{3}$, BRAGA, R.R. ${ }^{4}$, CARVALHO, F.P. ${ }^{5}$, VALADÃO SILVA, D. ${ }^{5}$ \\ e BYRRO, E.C.M. ${ }^{4}$
}

\begin{abstract}
RESUMO - Apesar do ciclo efetivamente rápido do feijoeiro, a habilidade no uso dos nutrientes adicionados por ocasião do plantio e cobertura pode ser prejudicada pela presença de determinadas espécies de plantas daninhas. Objetivou-se com este trabalho avaliar os efeitos da competição entre três cultivares de feijão (IPR Colibri, IPR Eldorado e Pérola) e seis espécies de plantas daninhas (Euphorbia heterophylla, Bidens pilosa, Cenchrus echinatus, Amaranthus spinosus, Commelina benghalensis e Brachiaria plantaginea) no acúmulo de N, P e K pelas plantas e na eficiência nutricional do feijoeiro. O experimento foi realizado em condições controladas de temperatura e umidade, em delineamento de blocos casualizados, com quatro repetições. O periodo de convivência entre os cultivares de feijão e as plantas daninhas foi de 45 dias após emergência da cultura. Os cultivares de feijão apresentaram reduzido acúmulo relativo de $\mathrm{N}, \mathrm{P}$ e $\mathrm{K}$ quando estavam em competição, sendo o sistema radicular o principal órgão afetado negativamente. O cultivar IPR Colibri foi o que menos tolerou a competição com plantas daninhas e $E$. heterophylla foi a espécie com menor poder de competição, enquanto A. spinosus e B. plantaginea foram as mais competitivas com a cultura do feijão. A eficiência nutricional do feijoeiro variou conforme o genótipo de feijão e a espécie infestante.
\end{abstract}

Palavras-chave: Euphorbia heterophylla, Bidens pilosa, Cenchrus echinatus, Amaranthus spinosus, Commelina benghalensis, Brachiaria plantaginea.

\begin{abstract}
Although the common bean has an effectively rapid cycle, its ability to use nutrients added during planting and cover can be affected by the presence of certain weed species. The objective of this study was to evaluate the effects of competition between three bean cultivars (IPR Colibri, IPR Eldorado, and Pérola) and six weed species (Euphorbia heterophylla, Bidens pilosa, Cenchrus echinatus, Amaranthus spinosus, Commelina benghalensis and Brachiaria plantaginea) on accumulation of $N, P$, and $K$ by the plants, and on the nutritional efficiency of the bean plant. The experiment was conducted under controlled temperature and humidity conditions in a randomized block design with four replications. The period of coexistence between the bean cultivars and the weeds was 45 days after crop emergence. The bean cultivars showed reduced relative accumulation of $N, P$, and $K$ when under competition, with the root system being the main organ affected negatively. IPR Colibri tolerated competition with the weeds the least. $\boldsymbol{E}$. heterophylla presented the lowest competitive power, while A. spinosus and B. plantaginea were the most competitive against the bean. The nutritional efficiency of the bean plants varied according to the bean genotype and the weed.
\end{abstract}

Keywords: Euphorbia heterophylla, Bidens pilosa, Cenchrus echinatus, Amaranthus spinosus, Commelina benghalensis, Brachiaria plantaginea.

1 Recebido para publicação em 30.3.2011 e aprovado em 27.6.2012.

2 Mestre em Produção Vegetal pelo Programa de Pós-Graduação em Produção Vegetal - PPGPV, Universidade Federal dos Vales do Jequitinhonha e Mucuri - UFVJM, <joaopcury@yahoo.com.br>; ${ }^{3}$ Docentes Permanentes do PPGPV/UFVJM, <barbosa@pq.cnpq.br>, <ebsilva@ufvjm.edu.br>; ${ }^{4}$ Mestrandos, PPGPV/UFVJM, <granderenan@gmail.com>, <elizabyrro@hotmail.com>; ${ }^{5}$ Doutorandos do Programa de Pós-Graduação em Fitotecnia da Universidade Federal de Viçosa DFT/UFV), <danielvaladaos@yahoo.com.br>,<felipepaolinelli@yahoo.com.br>.

Planta Daninha, Viçosa-MG, v. 31, n. 1, p. 79-88, 2013 


\section{INTRODUÇÃO}

Para que a cultura do feijoeiro expresse o máximo do seu potencial produtivo, é necessário o controle de fatores limitantes, entre os quais se destaca a competição imposta pelas plantas daninhas. A comunidade infestante pode mobilizar grande quantidade de nutrientes e água do solo e reduzir, portanto, um recurso já insuficiente para as plantas cultivadas (Salgado et al., 2006).

Tem sido comum em culturas como feijoeiro e tomateiro maiores teores relativos de $\mathrm{N}, \mathrm{P}$ e K na parte aérea das plantas daninhas infestantes dessas culturas (Qasem, 1992). Populações de Desmodium tortuosum (Procópio et al., 2005) e Nicandra physaloides (Ronchi et al., 2003) foram capazes de acumular, respectivamente, até 10 e 15 vezes a quantidade relativa de fósforo que a cultura que infestavam. Santos et al. (1998) reportaram que a competição de Amaranthus hybridus com alface ocasionou aumento do conteúdo total de P nessa planta daninha e diminuição nas plantas de alface. No entanto, existem poucos relatos na literatura sobre a importância das características da planta cultivada na determinação do seu potencial competitivo com espécies de ocorrência natural (não cultivadas), o que dificulta a seleção de cultivares mais hábeis em competir com plantas daninhas quando se visa elevar o patamar de competitividade das culturas agrícolas (Balbinot Jr. et al., 2003).

Diversos autores relatam características morfofisiológicas que podem estar diretamente relacionadas à habilidade competitiva superior das culturas, como: matéria seca da parte aérea (Lamego et al., 2005), distribuição espacial (Dias et al., 2010), germinação e emergência (Carvalho \& Christoffoleti, 2008), estatura (Mcdonald, 2003), hábito de crescimento (Teixeira et al., 2009), indice de área foliar (Haefele et al., 2004), cobertura do solo (Balbinot Jr. et al., 2003), interceptação da radiação solar (Carvalho \& Christoffoleti, 2008) e densidade foliar na parte superior da planta (Caton et al., 2001). No entanto, a capacidade de aporte e alocação de nutrientes varia com as espécies envolvidas, e nem sempre é dada a devida atenção e a relevância necessária.

Acredita-se que alguns fatores genéticos podem proporcionar diferenças nos teores foliares de nutrientes minerais, indicando que entre os cultivares existe maior ou menor eficiência na absorção, na translocação ou na utilização de nutrientes pela planta (Augusto et al., 2007). Essas eficiências são compreendidas como de ordem nutricional e estão associadas a características morfofisiológicas das plantas. Inúmeros trabalhos com culturas agrícolas demonstram a existência de variabilidade dessa eficiência entre espécies e entre cultivares de uma mesma espécie, o que sugere ocorrência de controle genético da nutrição (Sacramento \& Rosolem, 1998). Dessa forma, verifica-se a possibilidade de melhora e/ou seleção de cultivares com maior eficiência nutricional. Como consequência, o emprego de técnicas de manejo que optem por esses cultivares poderá resultar em cultivos agrícolas com menor consumo energético e com maior eficiência de aproveitamento dos fertilizantes aplicados, reduzindo o custo com insumos, evitando a perda de nutrientes pelo sistema edafoclimático e conservando os ecossistemas agrícolas existentes.

A hipótese desta pesquisa é de que há variação na capacidade de diferentes espécies vegetais, cultivadas ou não, de absorver e redistribuir os nutrientes quando em competição e de que há variação na eficiência nutricional dos cultivares de feijão em decorrência dessa convivência. Nesse contexto, este trabalho teve como objetivo determinar os efeitos da competição entre cultivares de feijão e plantas daninhas no acúmulo e partição de $\mathrm{N}, \mathrm{P}$ e K pelas plantas, bem como avaliar a eficiência de absorção, transporte e utilização desses nutrientes pelo feijoeiro, visando adquirir subsídios para orientação de trabalhos de melhoramento vegetal na seleção de genótipos superiores para competir com plantas concorrentes.

\section{MATERIAL E MÉTODOS}

O experimento foi conduzido em ambiente protegido, com condições controladas de temperatura e umidade. Utilizou-se de Latossolo Vermelho-Amarelo Distrófico típico, textura argilosa (56\% de argila, $6 \%$ de silte e $38 \%$ de areia). A análise química do solo apresentou pH (água) de 5,4; teor de matéria orgânica de 1,8 daq kg-1; $\mathrm{P}, \mathrm{K}, \mathrm{Ca}, \mathrm{Mg}, \mathrm{Al}, \mathrm{H}+\mathrm{Al}$ e CTC $_{\text {efetiva }}$ de 1,$4 ; 10 ; 0,5 ; 0,2 ; 0,4 ; 4,4 ;$ e $1,7 \mathrm{cmol}_{\mathrm{c}} \mathrm{dm}^{-3}$, 
respectivamente. Para adequação do substrato quanto à nutrição, foram aplicados $3,0 \mathrm{~g} \mathrm{dm}^{3}$ de calcário dolomítico e $2,9 \mathrm{~g} \mathrm{dm}^{3}$ da formulação 4-14-8 (N- $\left.\mathrm{P}_{2} \mathrm{O}_{5}-\mathrm{K}_{2} \mathrm{O}\right)$. A adubação complementar nitrogenada em cobertura foi realizada em intervalos de 15 dias após a emergência da cultura (DAE), na dose de $31,0 \mathrm{mg} \mathrm{dm}^{-3} \mathrm{de}$ ureia previamente dissolvida em água. Aos 15 e $25 \mathrm{DAE}$ foram efetuadas duas pulverizações foliares de 77,0 $\mathrm{g} \mathrm{ha}^{-1}$ de molibdênio em cada aplicação, na forma de molibdato de sódio $\left(\mathrm{Na}_{2} \mathrm{MoO}_{4} \cdot 2 \mathrm{H}_{2} \mathrm{O}\right)$. As irrigações foram realizadas diariamente, por sistema automático de microaspersão.

O delineamento experimental utilizado foi de blocos casualizados com quatro repetições, com arranjo fatorial em esquema $3 \times 6+9$, constituído pela combinação de três genótipos de feijão (IPR Colibri, IPR Eldorado e Pérola) em competição com seis espécies de plantas daninhas: Euphorbia heterophylla (EPHHL), Bidens pilosa (BIDPI), Cenchrus echinatus (CCHEC), Amaranthus spinosus (AMASP), Commelina benghalensis (COMBE) e Brachiaria plantaginea (BRAPL) e, ainda, por nove tratamentos adicionais, correspondentes aos cultivares de feijão e às espécies daninhas ausentes de competição. Os cultivos foram realizados em vasos de polietileno com capacidade volumétrica de 5,0 L $(25,0 \times 21,0 \mathrm{~cm}$ de diâmetro e altura, respectivamente), contendo amostra de solo.

Mudas de $C$. benghalensis foram transplantadas, e as demais espécies de plantas daninhas foram semeadas diretamente nos vasos, aos 15 dias antes da semeadura dos cultivares de feijão, de forma a coincidir com a emergência da cultura e possibilitar a expressão do potencial competitivo inerente à biologia dessas espécies. Para as espécies semeadas, as densidades almejadas foram mantidas por meio de desbastes. O experimento foi composto pela mesma densidade de plantas daninhas e plantas de feijão (uma planta por vaso) - exceto para a espécie $E$. heterophylla, que possuía a densidade de duas plantas por vaso. Os valores para densidade foram preestabelecidos após estudos de fitossociologia em áreas de cultivo de feijão sobre o mesmo tipo de solo (dados não apresentados).

Aos 45 dias após a emergência e convivência da cultura com as espécies infestantes, para determinação da matéria seca, procedeuse à retirada das plantas de feijão e, também, das plantas daninhas, separando-as em raizes, caules e folhas. Esse intervalo foi estabelecido com o intuito de quantificar os prejuízos da convivência do feijoeiro com plantas daninhas durante o período crítico de prevenção da interferência de espécies infestantes, que pode ser estendido até aproximadamente 58 dias após a emergência da cultura (Kozlowski et al., 2002).

Após essa coleta, todo o material vegetal foi lavado em água destilada e seco em estufa com circulação forçada de ar, a $65^{\circ} \mathrm{C}$, até massa constante. Todo o material seco foi moído, em moinho tipo Wiley, homogeneizado e amostrado para se fazer a determinação dos teores de $\mathrm{N}, \mathrm{P}$ e $\mathrm{K}$ entre os componentes vegetativos dos cultivares de feijão e das diferentes espécies de plantas daninhas. Para as espécies $C$. echinatus e $B$. plantaginea, a bainha foi somada às folhas, e o colmo, comparado com o caule. Os teores de N, P e K foram determinados segundo metodologia descrita por Malavolta et al. (1997). A partir da matéria seca dos órgãos vegetais e de seus respectivos teores desses nutrientes, foram calculados os conteúdos nessas plantas.

Para a interpretação dos resultados, foi calculado o conteúdo relativo de N, P e K nos componentes vegetativos dos cultivares de feijão e das espécies daninhas. Atribuiu-se o valor de $100 \%$ ao conteúdo de N, P e K verificado nas plantas de feijão e de espécies daninhas que cresceram livres de convivência. A partir desse valor referencial, foram calculados os conteúdos percentuais (conteúdos relativos) de $\mathrm{N}, \mathrm{P}$ e K na matéria seca das plantas de feijão e daninhas que conviveram no mesmo vaso.

A partir da matéria seca e do conteúdo dos nutrientes nas plantas de feijão, foram calculados os seguintes índices de eficiência de absorção, transporte e utilização de N, P e $\mathrm{K}$ :

a) Eficiência na absorção (EA) de N, P e K: conteúdo de $\mathrm{N}$, P e K na planta $(\mathrm{mg})$ / matéria seca de raízes $(\mathrm{g})$.

b) Eficiência no transporte (ET) de N, P e $\mathrm{K}$ : [conteúdo de $\mathrm{N}, \mathrm{P}$ e $\mathrm{K}$ na parte aérea (mg) / conteúdo de N, P e K na planta (mg)] x 100.

Planta Daninha, Viçosa-MG, v. 31, n. 1, p. 79-88, 2013 
c) Eficiência na utilização (EU) de N, P e K: matéria seca total produzida (g)/conteúdo de N, P e K na planta (mg).

Os dados foram submetidos à análise de variância, e as médias, quando significativas, comparadas pelo teste de Tukey a $5 \%$ de probabilidade.

\section{RESULTADOS E DISCUSSÃO}

$\mathrm{O}$ conteúdo relativo $(\mathrm{CR})$ de $\mathrm{N}, \mathrm{P}$ e $\mathrm{K}$ nos componentes vegetativos do feijoeiro foi reduzido devido à competição com plantas daninhas (Tabela 1). O grau de interferência variou com os cultivares de feijão e com as diferentes espécies infestantes. Euphorbia heterophylla e Cenchrus echinatus afetaram negativamente o CR das plantas de feijão (Tabela 1). Sob interferência de $E$. heterophylla, o feijoeiro apresentou CRT médio de N (54\%), P (53\%) e K (63\%). $\mathrm{O}$ cultivar IPR Eldorado foi menos tolerante à competição imposta por essa espécie, apresentando reduzido acúmulo desses nutrientes no caule e na raiz. Entretanto, sob interferência de Cenchrus echinatus, esse cultivar foi o mais competitivo, devido, principalmente, ao maior acúmulo relativo de $\mathrm{N}(63 \%), \mathrm{P}(65 \%)$ e $\mathrm{K}(65 \%)$ nas folhas (Tabela 1). Constatou-se também que, em competição com esta espécie, o

Tabela 1 - Conteúdo relativo de N, P e K nos componentes vegetativos de cultivares de feijão sob interferência de diferentes plantas daninhas

\begin{tabular}{|c|c|c|c|c|c|c|c|c|c|c|c|c|}
\hline \multicolumn{13}{|c|}{$\mathrm{CRT}^{1 / /}(\%)$} \\
\hline \multirow{2}{*}{ Espécie } & \multicolumn{3}{|c|}{ FEIJÃO $^{2 /}$} & \multicolumn{3}{|c|}{ IPR Colibri } & \multicolumn{3}{|c|}{ IPR Eldorado } & \multicolumn{3}{|c|}{ Pérola } \\
\hline & $\mathrm{N}$ & $\mathrm{P}$ & $\mathrm{K}$ & $\mathrm{N}$ & $\mathrm{P}$ & $\mathrm{K}$ & $\mathrm{N}$ & $\mathrm{P}$ & $\mathrm{K}$ & $\mathrm{N}$ & $\mathrm{P}$ & $\mathrm{K}$ \\
\hline Testemunha $a^{3 /}$ & 100 & 100 & 100 & 100 & 100 & 100 & 100 & 100 & 100 & 100 & 100 & 100 \\
\hline EPHHL & 54 & 53 & 63 & 57 & 61 & 79 & 45 & 41 & 51 & 59 & 56 & 60 \\
\hline BIDPI & 41 & 39 & 37 & 29 & 31 & 30 & 47 & 48 & 45 & 47 & 38 & 36 \\
\hline CCHEC & 49 & 52 & 43 & 45 & 57 & 40 & 59 & 65 & 55 & 45 & 37 & 37 \\
\hline AMASP & 15 & 15 & 11 & 9 & 10 & 8 & 15 & 13 & 13 & 22 & 19 & 12 \\
\hline COMBE & 62 & 63 & 61 & 33 & 31 & 34 & 85 & 89 & 79 & 72 & 70 & 67 \\
\hline BRAPL & 16 & 13 & 12 & 15 & 14 & 13 & 8 & 5 & 5 & 26 & 20 & 18 \\
\hline \multicolumn{13}{|c|}{ Folha (\%) } \\
\hline Testemunha $^{3 /}$ & 100 & 100 & 100 & 100 & 100 & 100 & 100 & 100 & 100 & 100 & 100 & 100 \\
\hline EPHHL & 55 & 54 & 67 & 64 & 53 & 67 & 44 & 52 & 67 & 56 & 55 & 67 \\
\hline BIDPI & 35 & 37 & 37 & 24 & 27 & 22 & 42 & 55 & 53 & 41 & 38 & 41 \\
\hline CCHEC & 47 & 48 & 48 & 39 & 48 & 36 & 63 & 65 & 65 & 43 & 37 & 48 \\
\hline AMASP & 13 & 16 & 12 & 7 & 10 & 6 & 15 & 18 & 16 & 19 & 22 & 16 \\
\hline COMBE & 62 & 56 & 58 & 30 & 25 & 27 & 92 & 89 & 93 & 74 & 70 & 67 \\
\hline BRAPL & 13 & 15 & 14 & 13 & 14 & 11 & 7 & 5 & 7 & 19 & 23 & 22 \\
\hline \multicolumn{13}{|c|}{ Caule (\%) } \\
\hline Testemunha ${ }^{3 /}$ & 100 & 100 & 100 & 100 & 100 & 100 & 100 & 100 & 100 & 100 & 100 & 100 \\
\hline EPHHL & 58 & 52 & 59 & 58 & 77 & 70 & 49 & 34 & 36 & 65 & 52 & 68 \\
\hline BIDPI & 59 & 41 & 40 & 46 & 39 & 42 & 60 & 41 & 39 & 71 & 41 & 39 \\
\hline CCHEC & 60 & 54 & 46 & 50 & 72 & 48 & 68 & 61 & 53 & 63 & 38 & 40 \\
\hline AMASP & 25 & 23 & 17 & 19 & 18 & 12 & 23 & 25 & 23 & 32 & 24 & 16 \\
\hline COMBE & 70 & 64 & 65 & 37 & 53 & 44 & 88 & 77 & 73 & 86 & 59 & 71 \\
\hline BRAPL & 33 & 22 & 19 & 24 & 25 & 24 & 17 & 8 & 9 & 56 & 30 & 25 \\
\hline \multicolumn{13}{|c|}{ Raiz (\%) } \\
\hline Testemunha $^{3 /}$ & 100 & 100 & 100 & 100 & 100 & 100 & 100 & 100 & 100 & 100 & 100 & 100 \\
\hline EPHHL & 50 & 53 & 51 & 55 & 76 & 70 & 38 & 32 & 44 & 60 & 61 & 48 \\
\hline BIDPI & 40 & 39 & 36 & 31 & 34 & 40 & 50 & 50 & 46 & 37 & 31 & 26 \\
\hline CCHEC & 42 & 41 & 32 & 62 & 72 & 48 & 33 & 25 & 32 & 38 & 37 & 25 \\
\hline AMASP & 11 & 8 & 6 & 7 & 7 & 7 & 7 & 4 & 4 & 18 & 13 & 7 \\
\hline COMBE & 57 & 66 & 59 & 43 & 36 & 50 & 65 & 80 & 63 & 60 & 72 & 60 \\
\hline BRAPL & 11 & 7 & 7 & 11 & 9 & 9 & 5 & 3 & 3 & 17 & 11 & 9 \\
\hline
\end{tabular}

${ }^{1 /}$ Conteúdo relativo total; ${ }^{2 /}$ Média dos cultivares de feijão; ${ }^{3 /}$ Testemunha ausente de interferência de plantas daninhas; Euphorbia heterophylla (EPHHL), Bidens pilosa (BIDPI), Cenchrus echinatus (CCHEC), Amaranthus spinosus (AMASP), Commelina benghalensis (COMBE) e Brachiaria plantaginea (BRAPL). 
feijoeiro apresentou CRT médio de N (49\%), P $(52 \%)$ e $\mathrm{K}(43 \%)$, bem como severa redução desses nutrientes, principalmente em nivel radicular. É possivel inferir que a agressividade de $C$. echinatus abaixo da superficie do solo reduziu a disponibilidade desses nutrientes para o feijoeiro, provavelmente pelo maior desenvolvimento inicial de suas raízes e pela elevada habilidade dessa espécie em explorar e captar os nutrientes presentes no mesmo nicho ecológico que estavam sujeitos à competição. No entanto, a habilidade de captar recursos do solo e a habilidade competitiva de plantas não são necessariamente correlacionadas (Casper \& Jackson, 1997).

Sob interferência de Bidens pilosa, o CRT médio do feijoeiro foi de 41, 39 e 37\%, respectivamente para $\mathrm{N}, \mathrm{P}$ e $\mathrm{K}$ (Tabela 1 ). $\mathrm{O}$ acúmulo relativo de $\mathrm{N}(59 \%), \mathrm{P}(41 \%)$ e $\mathrm{K}(40 \%)$ no caule da cultura foi superior ao dos seus demais órgãos vegetais. É provável que a maior alocação de nutrientes para o caule tenha ocorrido pela tentativa do feijoeiro em sobrepor seu dossel ao da planta daninha, obtendo maior altura e vantagem na competição por luz. É importante ressaltar que as plantas cultivadas serão mais altas quanto maior for a competição imposta pelas plantas daninhas, desde que essa competição não reduza drasticamente os recursos do meio a ponto de restringir o crescimento da cultura (Carvalho et al., 2010). Notou-se, também, que o cultivar IPR Colibri foi menos tolerante à competição imposta por essa espécie, com reduzido acúmulo proporcional de N, P e K, principalmente nas folhas. De forma semelhante, sob interferência de Amaranthus spinosus, esse cultivar foi o menos competitivo, sendo a folha, novamente, o principal órgão afetado negativamente.

O CR de N, P e K do feijoeiro foi severamente reduzido devido à competição com A. spinosus (Tabela 1). Verificou-se CRT médio desses nutrientes inferior a $16 \%$. A raiz foi o principal componente vegetativo do feijoeiro afetado negativamente por essa interferência, o que pode caracterizar desvantagem da cultura em competir por água e nutrientes. Esses resultados são contrários aos observados por Carvalho \& Christoffoleti (2008), os quais concluíram que, em proporções equivalentes de plantas, o feijoeiro é mais competitivo que
A. spinosus e outras quatro espécies de caruru (Amaranthus spp.).

O CRT médio de N, P e K do feijoeiro foi severamente reduzido devido à competição com Brachiaria plantaginea (Tabela 1). Verificou-se acúmulo relativo médio desses nutrientes inferior a $17 \%$, em relação à média das testemunhas. Esse efeito é ainda mais visível na raiz, onde o CR foi de $11 \%$ para $\mathrm{N}$ e de $7 \%$ para $\mathrm{Pe} \mathrm{K}$. Constatou-se, também, que o cultivar Pérola foi o mais competitivo, em função, principalmente, do elevado acúmulo proporcional de N, P e K na parte aérea de suas plantas, em relação à testemunha e ao acumulado nos mesmos órgãos pelos demais cultivares de feijão. De forma contrária, o cultivar IPR Eldorado foi menos tolerante à competição com essa espécie, obtendo reduzido CR em todos os seus componentes vegetativos.

Commelina benghalensis foi a espécie daninha que promoveu a menor redução do $C R$ do feijoeiro (Tabela 1). Verificou-se que o CRT médio do feijoeiro foi de 62, 63 e 61\%, respectivamente para N, P e K. O cultivar IPR Colibri foi menos tolerante à competição imposta por essa espécie, com severa redução do $\mathrm{CR}$ em todos os seus componentes vegetativos, apresentando acúmulo proporcional de N, P e K inferior ao da média das testemunhas e dos demais cultivares. O cultivar IPR Eldorado mostrou-se o mais competitivo, com acúmulo relativo desses nutrientes superior ao obtido pelos demais cultivares.

De maneira geral, o cultivar IPR Colibri foi menos competitivo, com menor tolerância à interferência de plantas daninhas (Tabela 1). A duração do ciclo e o hábito de crescimento do feijoeiro podem ter relação direta com a habilidade do cultivar em tolerar a competição imposta pelas plantas daninhas na fase inicial. Por apresentar hábito de crescimento do tipo I, diferentemente dos demais cultivares (IPR Eldorado - tipo II e Pérola - tipo II/III), e possuir porte ereto e menor número de ramificações, haverá menor cobertura do solo e, consequentemente, menor habilidade competitiva (Teixeira et al., 2009). Esse comportamento corrobora os resultados obtidos por Andrade et al. (1999) e Teixeira et al. (2009).

Constatou-se que o $\mathrm{CR}$ dos cultivares de feijão foi severamente reduzido devido à 
competição com as diferentes espécies de plantas daninhas, principalmente em nivel radicular (Tabela 1). Contudo, as espécies infestantes também sofreram de forma pronunciada com essa convivência (Tabela 2). Verificou-se que o CRT médio de $E$. heterophylla foi de $24 \%(\mathrm{~N}), 22 \%(\mathrm{P})$ e $16 \%(\mathrm{~K})$. O acúmulo relativo de nutrientes dessa espécie foi reduzido sobretudo pela competição com o cultivar IPR Colibri. No entanto, esse cultivar foi responsável pelo elevado CR de $\mathrm{N}$ na folha (139\%) e no caule $(106 \%)$ de $C$. echinatus (Tabela 2$)$.

Em convivência com o feijoeiro, B. pilosa e C. echinatus apresentaram menor acúmulo relativo de $\mathrm{K}(55 \%)$, em relação às respectivas testemunhas livres de interferência (Tabela 2). A folha de $B$. pilosa foi o principal órgão afetado negativamente pela competição, com reduzido acúmulo proporcional de N (60\%), P (65\%) e K $(42 \%)$.

Amaranthus spinosus e B. plantaginea demonstraram ser as espécies com maior capacidade de competição, pois, além de afetarem negativamente o CR em todos os componentes vegetativos da cultura, apresentaram elevados valores desse indice sob competição, comparados com os obtidos pelas demais espécies daninhas (Tabela 2). O CRT médio de $A$. spinosus sofreu poucas modificações devido à convivência com a cultura, sem prejuízos quanto ao acúmulo relativo de $\mathrm{N}$ (101\%), P (97\%) e K (105\%), ao passo que o CRT médio de $B$. plantaginea foi superior ao da cultura para todos os nutrientes, apresentando elevado acúmulo proporcional de $\mathrm{N}$ (81\%), P (114\%) e K (101\%). Esta espécie, mesmo em convivência com os cultivares de feijão, acumulou quantidades elevadas de N (119\%), P $(135 \%)$ e K (134\%) nas folhas. Esse mesmo comportamento foi observado para o CR nas folhas e no caule de $A$. spinosus, que foram superiores em 29 e 39\% para N e K, respectivamente. Esse fato foi verificado na competição dessa espécie com os três cultivares de feijão, demonstrando que, independentemente do genótipo competidor, o acúmulo de nutrientes na parte aérea de $A$. spinosus foi favorecido por essa convivência.

Tem sido observada na literatura a associação de bactérias diazotróficas (Hungria et al., 1997), fungos micorrízicos arbusculares
(Hungria et al., 1997) e bactérias do gênero Rhizobium (Amarger et al., 1997) com a cultura do feijoeiro. Conforme Hungria et al. (1997), a presença do feijoeiro, em monocultura ou em consórcio com o milho, estimulou a biomassa microbiana, o potencial nitrificante, o número de células e a biodiversidade de Rhizobium e o número de espécies de fungos. Plantas de feijão também exsudam compostos fenólicos e flavonoides (Hungria et al., 1991a,b). Diante disso, é provável que plantas de C. echinatus, $B$. plantaginea e $A$. spinosus não somente absorveram os nutrientes essenciais presentes no substrato, como também se aproveitaram das substâncias exsudadas e das interações do feijoeiro com microrganismos. Isso corrobora a ideia de que a inter-relação entre plantas denota ser variável ainda pouco elucidada e nem sempre pode ser considerada danosa para as espécies envolvidas, uma vez que essas espécies de plantas daninhas apresentaram maior acúmulo de nutrientes quando em convivência com cultivares de feijão. Além disso, considerando a "agressividade" que algumas espécies daninhas apresentam em condições de baixa disponibilidade dos recursos do meio, a eficiência em formar associações com microrganismos do solo pode responder pela maior viabilidade que essas espécies apresentam em competição com as culturas agrícolas (Santos et al., 2010). Conforme estes autores, a existência ou não de uma associação com microrganismos do solo pode ser decisiva diante de uma situação de competição, principalmente para a absorção de nutrientes.

A eficiência nutricional de cultivares de feijão em competição com espécies de plantas daninhas está representada na Tabela 3. Esta contém informações importantes para determinação da capacidade de diferentes genótipos de feijão em aproveitar o N, P e K quando submetidos às situações de estresse competitivo, possibilitando também a inferência sobre o consumo de nutrientes acima dos niveis adequados para a cultura e sobre seu potencial competitivo. As eficiências de absorção, transporte e utilização indicam a capacidade da planta em extrair nutrientes do meio de cultivo, converter o nutriente absorvido em matéria seca e redistribuir e reutilizar os elementos minerais, respectivamente (Rozane et al., 2007). 
Tabela 2 - Conteúdo relativo de N, P e K nos componentes vegetativos de plantas daninhas em convivência com cultivares de feijão

\begin{tabular}{|c|c|c|c|c|c|c|c|c|c|c|c|c|c|c|c|c|c|c|}
\hline \multirow{4}{*}{ Feijão } & \multicolumn{18}{|c|}{$\mathrm{CRT}^{1 /}(\%)$} \\
\hline & \multicolumn{18}{|c|}{ Espécie } \\
\hline & \multicolumn{3}{|c|}{ EPHHL } & \multicolumn{3}{|c|}{ BIDPI } & \multicolumn{3}{|c|}{ CCHEC } & \multicolumn{3}{|c|}{ AMASP } & \multicolumn{3}{|c|}{ COMBE } & \multicolumn{3}{|c|}{ BRAPL } \\
\hline & $\mathrm{N}$ & $\mathrm{P}$ & $\mathrm{K}$ & $\mathrm{N}$ & $\mathrm{P}$ & $\mathrm{K}$ & $\mathrm{N}$ & $\mathrm{P}$ & $\mathrm{K}$ & $\mathrm{N}$ & $\mathrm{P}$ & $\mathrm{K}$ & $\mathrm{N}$ & $\mathrm{P}$ & $\mathrm{K}$ & $\mathrm{N}$ & $\mathrm{P}$ & $\mathrm{K}$ \\
\hline Testemunha $\mathrm{a}^{2}$ & 100 & 100 & 100 & 100 & 100 & 100 & 100 & 100 & 100 & 100 & 100 & 100 & 100 & 100 & 100 & 100 & 100 & 100 \\
\hline FEIJÃO ${ }^{3 /}$ & 24 & 22 & 16 & 66 & 64 & -55 & 83 & 61 & 55 & 101 & 97 & 105 & 42 & 42 & 51 & 81 & 114 & 101 \\
\hline IPR Colibri & 10 & $-\overline{8}$ & $-\overline{7}$ & $\overline{7} \overline{4}$ & $\overline{73}$ & $\overline{56}$ & $-\overline{114}$ & 77 & 78 & 103 & 92 & 99 & 42 & 43 & 51 & 80 & 102 & 91 \\
\hline IPR Eldorado & 43 & 40 & 28 & 66 & 63 & 46 & 74 & 57 & 30 & 103 & 89 & 106 & 38 & 40 & 47 & 95 & 130 & 109 \\
\hline Perola & 18 & 16 & 12 & 59 & 57 & 63 & 62 & 48 & 55 & 97 & 109 & 111 & 47 & 43 & 56 & 67 & 109 & 102 \\
\hline \multicolumn{19}{|c|}{ Folha (\%) } \\
\hline Testemunha $^{2 /}$ & 100 & 100 & 100 & 100 & 100 & 100 & 100 & 100 & 100 & 100 & 100 & 100 & 100 & 100 & 100 & 100 & 100 & 100 \\
\hline FEIJÃO ${ }^{3 /}$ & 23 & 19 & 18 & 60 & 65 & 42 & 93 & 66 & 64 & 129 & 80 & 96 & 59 & 54 & 68 & 119 & 135 & 134 \\
\hline IPR Colibri & 11 & $-\overline{8}$ & $\overline{9}$ & $6 \overline{2}$ & 73 & 32 & 139 & 87 & 94 & 132 & 79 & 93 & 52 & 53 & 54 & 139 & 112 & 120 \\
\hline IPR Eldorado & 38 & 34 & 29 & 64 & 65 & 34 & 79 & 60 & 34 & 135 & 84 & 95 & 59 & 55 & 76 & 126 & 141 & 129 \\
\hline Perola & 19 & 15 & 16 & 53 & 57 & 60 & 62 & 51 & 63 & 119 & 78 & 101 & 67 & 54 & 73 & 92 & 152 & 152 \\
\hline \multicolumn{19}{|c|}{ Caule (\%) } \\
\hline Testemunha ${ }^{2 /}$ & 100 & 100 & 100 & 100 & 100 & 100 & 100 & 100 & 100 & 100 & 100 & 100 & 100 & 100 & 100 & 100 & 100 & 100 \\
\hline FEIJÃO ${ }^{3 /}$ & 20 & 19 & 20 & 71 & 64 & 66 & 80 & 54 & 45 & 90 & 88 & 139 & 34 & 33 & 42 & 65 & 140 & 94 \\
\hline IPR Colibri & $-\overline{7}$ & $-\overline{6}$ & 8 & $\overline{78}$ & $\overline{74}$ & 76 & $10 \overline{6}$ & 66 & 70 & 79 & 76 & 118 & 37 & 36 & 45 & 60 & 136 & 97 \\
\hline IPR Eldorado & 38 & 37 & 35 & 66 & 56 & 52 & 73 & 57 & 21 & 100 & 98 & 160 & 31 & 31 & 33 & 82 & 142 & 97 \\
\hline Perola & 14 & 14 & 15 & 70 & 61 & 69 & 60 & 39 & 43 & 92 & 91 & 137 & 35 & 32 & 47 & 53 & 142 & 88 \\
\hline \multicolumn{19}{|c|}{ Raiz (\%) } \\
\hline Testemunha $^{2 /}$ & 100 & 100 & 100 & 100 & 100 & 100 & 100 & 100 & 100 & 100 & 100 & 100 & 100 & 100 & 100 & 100 & 100 & 100 \\
\hline FEIJÃO ${ }^{3 /}$ & 35 & 33 & 18 & 80 & 68 & 72 & 80 & 64 & 67 & 72 & 91 & 76 & 20 & 21 & 26 & 64 & 85 & 62 \\
\hline IPR Colibri & 13 & 13 & 8 & 99 & 80 & 86 & 96 & 80 & 77 & 89 & 92 & 83 & 23 & 23 & 30 & 51 & 73 & 57 \\
\hline IPR Eldorado & 67 & 64 & 35 & 65 & 58 & 55 & 82 & 62 & 63 & 63 & 89 & 58 & 12 & 13 & 19 & 78 & 116 & 65 \\
\hline Perola & 24 & 22 & 10 & 76 & 67 & 76 & 63 & 49 & 61 & 64 & 92 & 86 & 24 & 27 & 28 & 64 & 65 & 63 \\
\hline
\end{tabular}

${ }^{1 /}$ Conteúdo relativo total; ${ }^{2} /$ Testemunha de planta daninha ausente de convivência com cultivares de feijão; ${ }^{3 /}$ Média de plantas daninhas em competição com cultivares de feijão; Euphorbia heterophylla (EPHHL), Bidens pilosa (BIDPI), Cenchrus echinatus (CCHEC), Amaranthus spinosus (AMASP), Commelina benghalensis (COMBE) e Brachiaria plantaginea (BRAPL).

Sob interferência de $B$. plantaginea, o feijoeiro apresentou maior eficiência média na absorção de N (EAN), em relação à média das testemunhas (Tabela 3). É possivel inferir que o feijoeiro, quando submetido à competição com essa espécie, aumentou sua capacidade de absorção de $\mathrm{N}$, na tentativa de resistir à limitação ou indisponibilidade desse nutriente. Esse fato pode estar relacionado com a alteração da morfologia e distribuição das raízes do feijoeiro, bem como com suas características fisiológicas ligadas à cinética de absorção desse nutriente. Contudo, é importante ressaltar que nem sempre maior absorção vai resultar em maior rendimento de grãos da cultura. Um genótipo pode absorver maior quantidade de nutrientes e estes ficarem retidos nas raízes ou serem acumulados em função da limitação de outros elementos. Dessa forma, é provável que os dois eventos supracitados tenham ocorrido, pois notou-se que os cultivares de feijão não apresentaram diferenças na eficiência média de transporte e utilização de N (ETN e EUN, respectivamente) em função dessa convivência (Tabela 3).

Sob interferência de $A$. spinosus, o feijoeiro apresentou maior eficiência média de absorção e transporte de P (EAP e ETP, respectivamente) (Tabela 3 ). Em competição com B. pilosa, a eficiência média de utilização de $\mathrm{P}$ (EUP) foi superior à da testemunha ausente de competição. Nesse caso, plantas de feijoeiro submetidas à competição com essas espécies daninhas possuem maior eficiência nutricional de $\mathrm{P}$, porém sem acréscimo de biomassa vegetal (dados não apresentados). É provável que a extração, a utilização e, principalmente, o transporte de $\mathrm{N}$ e $\mathrm{K}$ pelo feijoeiro, por não seguirem a mesma tendência do $\mathrm{P}$, tenham sido limitantes na conversão de nutrientes minerais em matéria seca. Assim, a limitação 


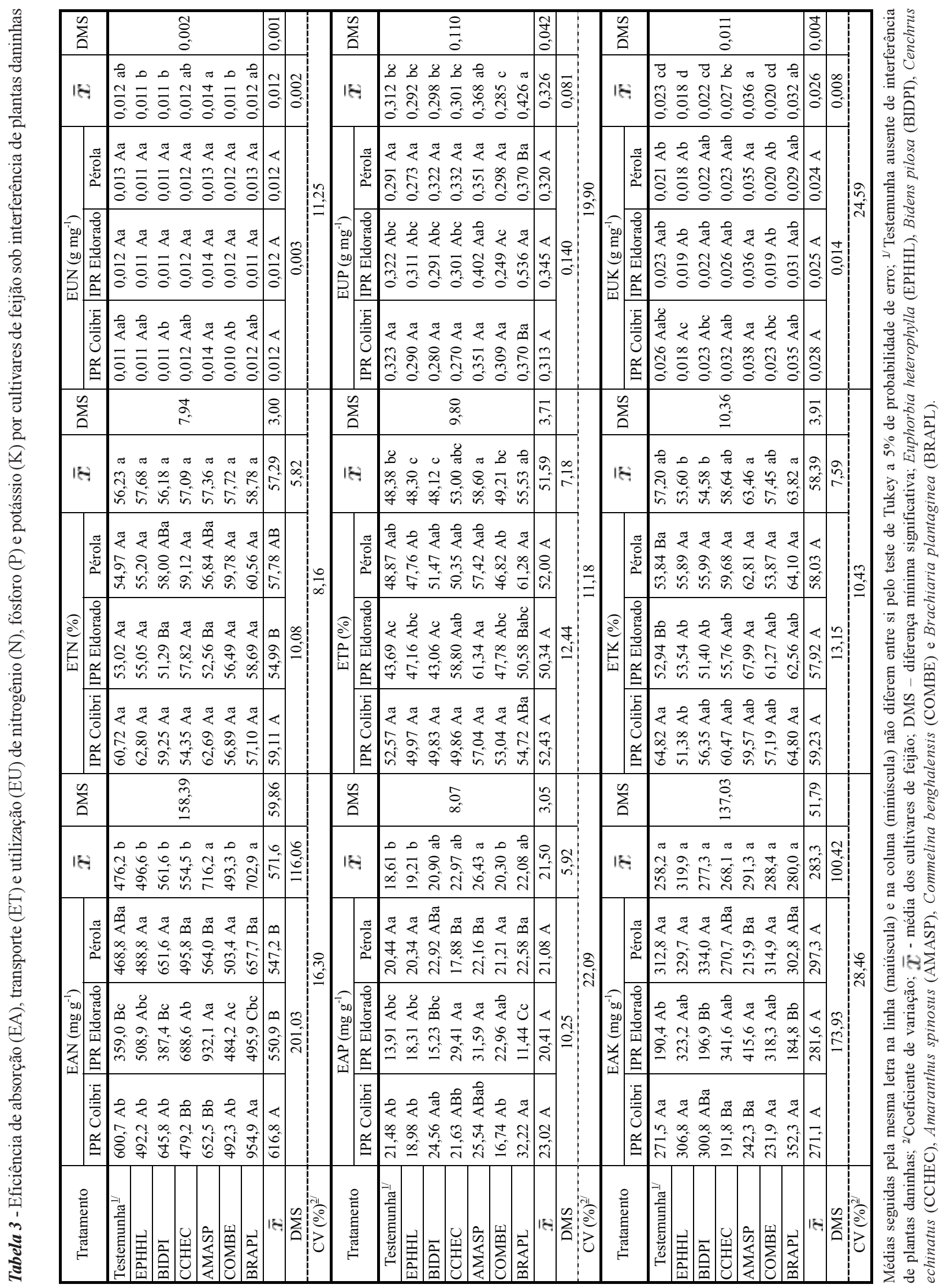


dos demais nutrientes diminui o acúmulo de biomassa vegetal. Além disso, este experimento avaliou o crescimento inicial do feijoeiro (até os $45 \mathrm{DAE}$ ). Provavelmente, ao longo de seu ciclo de desenvolvimento ocorrerá redução da eficiência nutricional de P.

Os cultivares de feijão não diferiram entre si no que se refere à eficiência média de absorção, transporte e utilização de K (EAK, ETK e EUK, respectivamente); a média da EAK apresentada pelo feijoeiro também não foi alterada em função da interferência imposta pelas diferentes espécies de plantas daninhas. No entanto, em competição com $A$. spinosus e $B$. plantaginea, o feijoeiro apresentou menor EUK média, em relação à média das testemunhas (Tabela 3).

Os cultivares de feijão avaliados, quando em competição com E. heterophylla e C. benghalensis, apresentaram reduzido $\mathrm{CR}$ de $\mathrm{N}, \mathrm{P}$ e K, porém essas espécies praticamente foram suprimidas pela cultura. O sistema radicular dos cultivares de feijão foi o principal órgão afetado negativamente pela competição. Observou-se que o cultivar IPR Colibri foi o que menos tolerou a competição com plantas daninhas. A. spinosus e B. plantaginea demonstraram ser as espécies com maior capacidade competitiva, pois afetaram negativamente o acúmulo proporcional de $\mathrm{N}, \mathrm{P}$ e K em todos os componentes vegetativos da cultura. Ademais, sofreram reduzidas modificações devido a essa convivência, sem prejuízos quanto ao acúmulo relativo desses nutrientes.

A eficiência de acúmulo, transporte e utilização de $\mathrm{N}, \mathrm{P}$ e $\mathrm{K}$ do feijoeiro variou conforme o genótipo de feijão e a espécie daninha competidora. Os resultados obtidos evidenciam a baixa capacidade de competição por nutrientes que a cultura do feijão apresenta. Torna-se evidente que a escolha de cultivares de feijão mais competitivos é necessária e viável para os agricultores, porque, além de possuir baixo custo, aprimora o manejo de espécies infestantes nos campos de produção agrícola.

\section{AGRADECIMENTOS}

Ao Conselho Nacional de Desenvolvimento Científico e Tecnológico (CNPq), à Fundação de Amparo à Pesquisa do Estado de Minas
Gerais (FAPEMIG) e à Coordenação de Aperfeiçoamento de Pessoal de Nivel Superior (CAPES), pelo apoio financeiro na execução deste trabalho.

\section{LITERATURA CITADA}

AMARGER, N. et al. Rhizobium gallicum sp. nov. and Rhizobium giardinii sp. nov., from Phaseolus vulgaris nodules. Inter. J. Syst. Bacteriol., v. 47, n. 4, p. 996-1006, 1997.

ANDRADE, C. A. B. et al. Efeito da competição com plantas daninhas em diferentes espaçamentos sobre o rendimento de três cultivares de feijão (Phaseolus vulgaris L.). Ci. Agrotec., v. 23 , n. 3, p. 529-539, 1999.

AUGUSTO, H. S. et al. Concentração foliar de nutrientes e cultivares de Coffea arabica L. sob espaçamentos adensados. Ci. Agrotec., v. 31, n. 4, p. 973-981, 2007.

BALBINOT Jr., A. A. et al. Características de plantas de arroz e a habilidade competitiva com plantas daninhas. Planta Daninha, v. 21, n. 2, p. 165-174, 2003.

CARVALHO, S. J. P.; CHRISTOFFOLETI, P. J.

Competition of Amaranthus species with dry bean plants. Sci. Agric., v. 65, n. 3, p. 239-245, 2008.

CARVALHO, L. B. et al. Interferência de Euphorbia heterophylla no crescimento e acúmulo de macronutrientes da soja. Planta Daninha, v. 28, n. 1, p. 33-39, 2010.

CASPER, B. B.; JACKSON, B. R. Plant competition underground. Ann. Rev. Ecol. Syst., v. 28, n. 1, p. 545-570, 1997.

CATON, B. P. et al. Weed shoot morphology effects on competitiveness for light in direct-seeded rice. WeedRes. v.41, n. 2, p. 155-163, 2001.

DIAS, A. C. R. et al. Competitiveness of alexandergrass or bengal dayflower with soybean. Planta Daninha, v. 28, n. 3, p. $515-522,2010$.

HAEFELE, S. M. et al. Field screening of diverse rice genotypes for weed competitiveness in irrigated lowland ecosystems. Field Crops Res., v. 88, n. 1, p. 39-56, 2004.

HUNGRIA, M. et al. Anthocyanidins and flavonols, major nod gene inducers from seeds of a black-seeded common bean (Phaseolus vulgaris L.). Plant Physiol., v. 97, n. 2, p. 751-758, 1991a.

HUNGRIA, M. et al. Rhizobium nod gene inducers exuded naturally from roots of common bean (Phaseolus vulgaris L.). Plant Physiol., v. 97, n. 2, p. 759-764, 1991 b. 
HUNGRIA, M. et al. Interação entre microrganismos do solo, feijoeiro e milho em monocultura ou consórcio. Pesq.

Agropec. Bras., v. 32, n. 8, p. 807-818, 1997.

KOZLOWSKI, L. A. et al. Período crítico de interferência das plantas daninhas na cultura do feijoeiro-comum em sistema de semeadura direta. Planta Daninha, v. 20, n. 2, p. 213-220, 2002 .

LAMEGO, F. P. et al. Tolerância a interferência de plantas competidoras e habilidade de supressão por cultivares de soja - I. Resposta de variáveis de crescimento. Planta Daninha, v. 23, n. 3 , p. $405-414,2005$.

MALAVOLTA, E. et al. Avaliação do estado nutricional das plantas: princípios e aplicações. Piracicaba: POTAFOS, 1997.

McDONALD, G. K. Competitiveness against grass weeds in field pea genotypes. Weed Res., v. 43, n. 1, p. 48-58, 2003.

PROCÓPIO, S. O. et al. Absorção e utilização do fósforo pelas culturas da soja e do feijão e por plantas daninhas. $\mathbf{R}$. Bras. Ci. Solo, v. 29, n. 6, p. 911-921, 2005.

QASEM, J. R. Nutrient accumulation by weeds and their associated vegetable crops. J. Hortic. Sci., v. 67, n. 2, p. 189-195, 1992.

RONCHI, C. P. et al. Acúmulo de nutrientes pelo cafeeiro sob interferência de plantas daninhas. Planta Daninha, v. 21, n. 2, p. 219-227, 2003.
ROZANE, D. E. et al. Eficiência de absorção, transporte e utilização de macronutrientes por porta enxertos de caramboleira, cultivados em soluções nutritivas. Ci. Agrotec., v. 31, n. 4, p. 1020-1026, 2007.

SACRAMENTO, L. V. S.; ROSOLEM, C. A. Eficiência de absorção e utilização de potássio por plantas de soja em solução nutritiva. Bragantia, v. 57, n. 2, p. 355-365, 1998.

SALGADO, T. P. et al. Efeitos da adubação fosfatada nas relações de interferência inicial entre plantas de milho (Zea mays) e de tiririca (Cyperus rotundus). Planta Daninha, v. 24, n. 1, p. 37-44, 2006.

SANTOS, B. M. et al. Phosphorus effects on competitive interactions of smooth pigweed (Amaranthus hybridus) and common purslane (Portulaca oleracea) with lettuce (Lactuca sativa). Weed Sci., v. 46, n. 3, p. 307-312, 1998.

SANTOS, E. A. et al. Atividade rizosférica de solo tratado com herbicida durante processo de remediação por Stizolobium aterrimum. Pesq. Agropec. Trop., v. 40, n. 1, p. 1-7, 2010 .

TEIXEIRA, I. R. et al. Competição entre feijoeiros e plantas daninhas em função do tipo de crescimento dos cultivares.

Planta Daninha, v. 27, n. 2, p. 235-240, 2009. 